\title{
Socio-Technical and Cultural Approaches to Energy Consumption An Introduction
}

\author{
Ana Horta, Harold Wilhite, Luísa Schmidt, \\ and Françoise Bartiaux
}

Energy consumption inconspicuously bridges nature and culture. Modern societies and cultures depend on intensive energy use from the extraction of natural resources. In fact, the industrialization process required large amounts of energy, but main sources such as oil and coal, have been gradually depleted and found to be heavily polluting the environment. Despite their environmental impacts, these resources have provided cheap and abundant power to fuel technological progress and economic growth. (See Agustoni and Maretti [2012] for a good historical summary of the relations between energy production and usages.)

The modes of energy production and consumption also reflect the relations that any society establishes with humans and non-humans. Descola (2012) interestingly puts forward the homology of the relations among humans, and between humans and nature, with his concept of "relational modes," or "integrating schemas." According to Descola, predation is the predominant relational mode in Western societies. Indeed, as cultural norms and social conventions have embodied the "need" of access to services and commodities developed and made available through intensive fossil energy consumption, energy exploitation has become an imperative of economic development. The massive use of machinery-in transport, communication, digital systems, entertainment, home design, and nearly all technologieswhich provide societies with the "dynamic character of modern social life" (Giddens 1991: 16) are almost invisibly dependent on energy use. This energy predatory mode is spreading globally with dramatic consequences for climate change.

Energy intensive consumption is continuing to increase and brings with it a dilemma: we need energy and carbon reduction at the same time (Wilhite 2012a). Therefore, it is crucial that we heed the words of O'Riordan (2012: 2), that "energy and society [need] to become sustainably compatible." For Szerszynski (2010) too, climate change 
bridges nature and culture. Energy-consuming practices show the interdependence between our societies and our relation with nature. Meeting the sustainability challenge will require addressing the complexity of political decisions and of socio-cultural change, questioning the role of consumption in modern life, and developing new forms for political instruments for enabling change.

The first studies on socio-cultural aspects of energy consumption were undertaken before the links between fossil energy consumption and climate change were clearly established. The oil embargos of the 1970s made the United States, European countries, and Japan aware for the first time of their vulnerability to oil imports. The domain of energy conservation was invented in order to decrease dependency on imports. The early science of energy conservation was mainly technical, focused on increasing the technical efficiency of energy production, transmission, and end use. It is not surprising that it did not take long to discover that end use involved not only technologies, but people. The Princeton Twin Rivers study was a landmark in revealing that energy use in identical dwellings varied dramatically (Socolow 1978). This opened discussion for explanations of that variation, and economics and psychology became the first social science disciplines to focus on energy conservation as a subject. In their models, economists and psychologists focused on individual end users whose behavior was driven by economic rationality and/or attitudes toward energy savings. "Behavioral anomalies" such as those exposed at Twin Rivers were said to be due to lack of information or motivation to save energy (Haines 1973; Stern 1986; Stern and Aronson 1984).

Individualist and rationalist models of end use became hegemonic models for the early social science of energy conservation. However, in the mid-1980s, a smattering of sociologists and social anthropologists directed their attention toward energy consumption. In the United States, many of these researchers gathered at the Families and Energy Conference, organized by Willett Kempton and Bonnie Morrison (1985) and held at the University of Michigan. A wide range of new perspectives on energy consumption were introduced involving culture, cognition, and other classic sociological subjects. Loren Lutzenhiser (1993) assimilated these early perspectives on "energy sociology."

Energy sociology bloomed in Europe in the 1990s. Some of the most interesting work was inspired by Elizabeth Shove at the University of Lancaster. She went against the grain of the mainstream social science interest in "conspicuous consumption," which postulated that energy consumption was driven by social performance and position- 
ing, and proposed that much of energy use in the home was mundane and inconspicuous. She and colleagues (Southerton and Shove 2000; Warde 1996) demonstrated how mundane consumption challenges neo-classical notions that demand comes from consumers. They argued that consumption was also related to the structuring of the built environment and to the choices delivered through systems of provision (Shove et al. 1998; Southerton et al. 2004; Wilhite et al. 2000). Further, Shove (2003) and Wilhite et al. (1996) introduced the idea of energy service (light, heat, comfort, convenience, cleanliness), pointing that people are not interested in consuming energy per se, but in the services they provide, and that the demand for these services is strongly influenced by cultural practices and social norms.

In the 2000s, the threads of these everyday practice perspectives were drawn together under the framework of social practice theory. These efforts drew on earlier work on practice theory by Bourdieu (1977) and Giddens (1991), revisited and renewed by Schatzki (1996) and Reckwitz (2002), and applied specifically to energy consumption by Warde (2005). Interest in this perspective has grown over the past decade. A special issue of the Journal of Consumer Culture was devoted to the application of social practice theory to consumption (Halkier et al. 2011). This perspective rejects rational choice and individual-focused theories of energy consumption, arguing for a view that energy consumption is a derivate of practices that develop in the interaction between people and things, in a socio-cultural space, over time. Practical knowledge is generated from these regular interactions, defined by Bourdieu as dispositions for future practices. Drawing on earlier work by Mauss (1934) and Merleau-Ponty (1962), recent research shows how practical knowledge is embodied and forms a competing source of agency in practices with cognitive, or reflexive knowledge (Warde and Southerton 2012). Practical knowledge is a source for the formation of routines and habits, largely ignored until recently in sustainable energy policy.

Another thread of energy consumption research that aims to capture the importance of human-material interactions derives from actornetwork theory. Akrich (1992), Verbeek (2005), and others have pointed to ways in which agency in consumption is distributed between human and non-human actors. In material dense societies such as those in Europe, the material environment has a strong structuring effect on consumption (Wilhite 2008). The synergies between actor-network theory and social practice theory form a promising platform for new developments in energy consumption research. 
These theoretical developments are especially relevant in times of economic crisis and transition to lower carbon systems and ways of life, both requiring reductions of energy consumption and more sustainable processes. The need for attention to the invisibility of social and environmental problems resulting from the dependence on intensive energy use brought about the organization of the first conference of the Energy \& Society network, held with the support of the European Sociological Association at the Institute of Social Sciences, University of Lisbon, in March 2012. One of the conference's major themes focused on social practices and cultural issues related to energy consumption. This special issue of Nature and Culture is comprised of articles presented at the conference on the issue of energy consumption. Holding these articles together is a discussion of how different elements (either social structures, like the public sphere or the family, or technologies) contribute to change or to socially reproduce energy cultures and practices of consumption.

The first article in this special issue denotes the existence of a hegemonic view of energy rooted in an anthropocentric perspective according to which energy is viewed as a commodity and a strategic material- "a thing that belongs to humans" — not as an ecological resource. Based on environmental psychology and a constructionist approach, Mauro Sarrica, Sonia Brondi, and Paolo Cottone analyze social representations of energy issues in Italian public discourses, focusing on parliamentary debates and newspaper articles from 2009 to 2011. In these discourses alternative representations related to sustainable energy are not able to challenge the hegemonic economic and strategic approaches, and even when decentralized energy systems are considered, citizens are required to stay passive, as otherwise they would be "an obstacle to top-down decisions, and ... should thus remain deficient."

The following article demonstrates the relevance of engaging citizens in sustainable energy transitions. By combining practice theory and domestication theory, Marianne Ryghaug and Marit Toftaker focus on the transformations in meanings, competences, and material aspects implicated in the adoption of a specific technology designed to reduce energy consumption: the electric car. The article highlights the role of design and comfort in electric driving and points to the possibility of creating communities of practice as a policy measure to promote these vehicles.

In the next article, Catherine Butler, Karen Anne Parkhill, Fiona Shirani, Karen Henwood, and Nick Pidgeon aim at understanding the 
connections between energy systems and social structures through the dynamics of energy demand by analyzing life-course transformations, ways of living, and energy-consuming practices. They propose biographical research as a valuable method for capturing and explaining both reductions and increases in energy consumption. Combining it with concepts of social reproduction and change, they discuss the role of agency in the understanding of how patterns of energy consumption are "made, remade and disrupted."

Focusing on the parents' perception of their children's practices of energy consumption and conservation, Luísa Schmidt, Ana Horta, Augusta Correia, and Susana Fonseca discuss the role of young people as agents of change by carrying knowledge on energy from schools to their homes. Despite environmental education and the current context of economic scarcity, the authors find energy consumption to be rooted in socialization processes, youth lifestyles and family everyday life, which induce young people to consume rather than to act as agents of change toward energy saving.

The relevance of family dynamics and interactions in shaping energy-consuming practices is also the focus of Françoise Bartiaux and Luis Reátegui Salmón's article. Framed by the social practice theories, this article is based on Reckwitz's famous statement: "the single individual acts as the "carrier' of a practice" and "consists in the unique crossing of different mental and bodily routines 'in' one mind/body and in the interpretative treatment of this constellation of 'crossing'" (2002: 256). Analyzing empirical data from a quantitative survey and e-mails, the authors propose an approach of practice theory enriched with more attention to social interactions at the household scale.

Each of the articles in this collection reflects an empirical grounding in practices of the relations between culture and nature and proposes suggestions for constructive theoretical and policy pathways toward more sustainable interactions between nature and culture.

Ana Horta is a post-doctoral researcher at the Institute of Social Sciences of the University of Lisbon, with a grant from the Portuguese Science and Technology Foundation. Address: ICS, Rua Prof. Aníbal de Bettencourt, 9, 1600-189 Lisboa, Portugal. E-mail: ana.horta@ics.ul.pt.

Harold Wilhite is professor of Social Anthropology and research director at the University of Oslo's Centre for Development and Environment. He has published widely on consumption, development, and societal change based on ethnographic field studies in North America, Latin America, Japan, Nor- 
way, and India. Address: University of Oslo, Centre for Development and the Environment, Oslo 0317, Norway. E-mail: h.I.wilhite@sum.uio.no.

Luísa Schmidt is a senior researcher at the Institute of Social Sciences at the University of Lisbon and the coordinator of OBSERVA-the Portuguese observatory of environment and society. Address: ICS, Rua Prof. Aníbal de Bettencourt, 9, 1600-189 Lisboa, Portugal. E-mail: schmidt@ics.ul.pt.

Françoise Bartiaux is professor of Environmental Sociology at the Université Catholique de Louvain and senior research associate at the National Fund for Scientific Research, also in Belgium. Address: UCL/SSH/IACS, Place Montesquieu 1/L2.08.03, B-1348-Louvain-la-Neuve, Belgium. E-mail: francoise.bartiaux@uclouvain.be.

\section{References}

Agustoni, Alfredo, and Mara Maretti. 2012. "Energy and Social Change: An Introduction." International Review of Sociology 22(3): 391-404.

Akrich, Madeleine. 1992. "The de-scription of Technical Objects." In Shaping Technology/Building Society: Studies in Sociotechnical Change, ed. Wiebe Eco Bijker and John Law, pp. 205-224. Cambridge, MA: MIT Press.

Bourdieu, Pierre. 1977. Outline of a Theory of Practice. Cambridge: Cambridge University Press.

Descola, Philippe. 2012. "Beyond Nature and Culture. Forms of Attachment." HAU: Journal of Ethnographic Theory 2 (1): 447-471.

Giddens, Anthony. 1991. Modernity and Self-Identity: Self and Society in the Late Modern Age. Stanford: Stanford University Press.

Haines, George. 1973. "Overview of Economic Models of Human Behavior." In Consumer Behavior: Theoretical Sources, ed. Scott Ward, and Thomas S. Robertson. pp. 276-300. Englewood Cliffs, NJ: Prentice Hall.

Halkier, Bente, Tally Katz-Gerro, and Lydia Martens. 2011. "Applying Practice Theory to the Study of Consumption: Theoretical and Methodological Considerations." Journal of Consumer Culture 11 (1): 3-13.

Kempton, Willett, and Bonnie Morrison, eds. 1985. Families and Energy, Coping with Uncertainty. Lansing: Michigan State University Press.

Lutzenhiser, Loren. 1993. "Social and Behavioral Sspects of Energy Use." Annual Review of Energy and the Environment 18: 247-289.

Mauss, Marcel. 1934. "Les techniques du corps." Journal de Psychologie 32 (3-4): 366-386.

Merleau-Ponty, Maurice. 1962. Phenomenology of Perception. London: Routledge.

O'Riordan, T. 2012. "Summary of the Workshop." Energy and Society Conference. http://www.energyandsociety.ics.ul.pt/p/presentations.html (accessed 2 June 2013).

Reckwitz, Andreas. 2002. "Toward a Theory of Social Practices: A Development of Culturist Theorizing." European Journal of Social Theory 5 (2): 243-263.

Schatzki, Theodore. 1996. Social Practices: A Wittgensteinian Approach to Human Activity and the Social. Cambridge: Cambridge University Press. 
Shove, Elizabeth. 2003. Comfort, Cleanliness and Convenience: The Social Organisation of Normality. Oxford and New York: Berg.

Shove, Elizabeth, Loren Lutzenhiser, Simon Guy, Bruce Hackett, and Harold Wilhite. 1998. "Energy and Social Systems." In Human Choice \& Climate Change. Volume 2: Resources and Technology, ed. Steve Rayner and Elizabeth L. Malone, pp. 291-325. Ohio: Battelle Press.

Socolow, Robert H., ed. 1978. Saving Energy in the Home: Princeton's Experiments at Twin Rivers. Cambridge: Ballinger.

Southerton, Dale, Heather Chappels, and Bas van Vliet, eds. 2004. Sustainable Consumption: The Implications of Changing Infrastructures of Provision. Cheltenham and Northampton: Edward Elgar.

Southerton, Dale, and Elizabeth Shove. 2000. "Defrosting the Freezer: From Novelty to Convenience. A Story of Normalization." Journal of Material Culture 5 (3): 301-319.

Stern, Paul. 1986. "Blind Spots in Policy Analysis: What Economics Doesn't Say about Energy Use." Journal of Policy Analysis and Management 5 (2): 200-227.

Stern, Paul, and Elliot Aronson, eds. 1984. Energy Use: The Human Dimension. Washington, DC: National Academy Press.

Szerszynski, Bronislaw. 2010. "Reading and Writing the Weather: Climate Technics and the Moment of Responsibility." Theory, Culture \& Society 27(2-3): 9-30.

Verbeek, Peter-Paul. 2005. What Things Do: Philosophical Reflections on Technology, Agency and Design. University Park: Pennsylvania State University Press.

Warde, Alan. 1996. "Afterword: The Future of the Sociology of Consumption." In Consumption Matters, ed. Steven Edgell, Kevin Hetherington, and Alan Warde. pp. 302-312. Oxford: Blackwell.

Warde Alan. 2005. "Consumption and Theories of Practice." Journal of Consumer Culture 5 (2): 131-153.

Warde, Alan, and Dale Southerton, eds. 2012. The Habits of Consumption, COLLeGIUM: Studies across Disciplines in the Humanities and Social Sciences, Volume 12. Helsinki: Helsinki Collegium for Advanced Studies.

Wilhite, Harold. 2008. "New Thinking on the Agentive Relationship between EndUse Technologies and Energy Using Practices." Journal of Energy Efficiency 1(2): 121-130.

Wilhite, Harold. 2012a. "The Energy Dilemma." Development and the Environment: Practices, Theories, Policies, ed. Kristian Bjørkdahl, and Kenneth Bo Nielsen, pp. 81-97. Oslo: Universitetsforlaget.

Wilhite, Harold. 2012b. "Towards a Better Accounting of the Roles of Body, Things and Habits in Consumption." In The Habits of Consumption, COLLeGIUM: Studies across Disciplines in the Humanities and Social Sciences, Volume 12, ed. Alan Warde, and Dale Southerton, pp. 87-99. Helsinki: Helsinki Collegium for Advanced Studies.

Wilhite, Harold, Hidetoshi Nakagami, Takashi Masuda, Yukiko Yamaga, and Hiroshi Haneda. 1996. "A Cross-Cultural Analysis of Household Energy-Use Behavior in Japan and Norway." Energy Policy 24 (9): 795-803.

Wilhite, Harold, Elizabeth Shove, Loren Lutzenhiser, and Willett Kempton. 2000. "The Legacy of Twenty Years of Demand Side Management: We Know More about Individual Behavior but Next to Nothing about Demand." In Society, Behaviour and Climate Change Mitigation, ed. Eberhard Jochem, Jayant Sathaye, and Daniel Bouille, pp. 109-126. Dordrecht: Kluwer Academic. 